\title{
Kelayakan Usaha Perbibitan Sapi Potong pada Kegiatan Pendampingan Pengembangan Kawasan Peternakan di Kabupaten Sigi
}

\author{
(Feasibility of Beef Cattle Breeding in the Development Area of Assistance Activities \\ Ranch in Sigi)
}

\author{
Asnidar, Dewi M, Takdir M, Amin M, Ishak ABL \\ Balai Pengkajian Teknologi Pertanian Sulawesi Tengah \\ Jl. Lasoso No. 62, Sigi Biromaru, Kabupaten Sigi, Sulawesi Tengah 94364 \\ nidar7477@gmail.com
}

\begin{abstract}
The study aims to determine the feasibility of breeding beef cattle herd managed by Bualo Jaya farmer group on development assistance activities in the area of beef cattle farms Sigi District. The research was conducted from January to December 2016 in the village of the District Pandere Gumbasa Sigi. Research using direct observation method in the field and survey to 30 farmers as respondents. Data collection consist of primary data directly from respondents through interviews using questionnaires and secondary data from the agency/technical agencies. Data were analyzed descriptively, feasibility analysis, revenue and break even point (BEP). The results showed that the net revenues is Rp 4.9442 million, break even point of production (BEP Q) 42 heads, the break even price (BEP S) Rp 5,635,193/head and R/C ratio of 1.24. It was concluded that the business of breeding beef cattle over 27 months is feasible and can be maintained as a source of additional income for the group and its members of Bualo Jaya farmer group.
\end{abstract}

Key Words: Feasibility, Breeding, Beef Cattle, Farmers Group

\begin{abstract}
ABSTRAK
Penelitian ini bertujuan untuk mengetahui kelayakan usaha perbibitan sapi potong yang dikelola oleh kelompok ternak Bualo Jaya pada kegiatan pendampingan pengembangan kawasan peternakan sapi potong di Kabupaten Sigi. Penelitian dilaksanakan pada bulan Januari-Desember 2016 di Desa Pandere Kecamatan Gumbasa Kabupaten Sigi. Penelitian menggunakan metode observasi langsung di lapangan dan survei responden terhadap 30 orang peternak. Data yang dikumpulkan terdiri dari data primer langsung dari responden melalui wawancara dengan menggunakan kuesioner dan data sekunder dari instansi/dinas teknis terkait. Data dianalisis secara deskriptif, analisis kelayakan, pendapatan dan titik impas (break even point/BEP). Hasil penelitian menunjukkan bahwa nilai pendapatan bersih sebesar Rp. 42.069.200, titik impas (BEP) produksi 42 ekor, BEP harga Rp. 5.635.193/ekor dan R/C ratio 1,24. Disimpulkan bahwa usaha perbibitan sapi potong yang dikelola kelompok ternak Bualo Jaya Desa Pandere Kecamatan Gumbasa Kabupaten Sigi selama 27 bulan layak dan dapat dipertahankan sebagai sumber pendapatan tambahan bagi kelompok ternak Bualo Jaya dan anggotanya.
\end{abstract}

Kata Kunci: Kelayakan Usaha, Perbibitan, Sapi Potong, Kelompok Ternak

\section{PENDAHULUAN}

Usaha perbibitan sapi potong memiliki prospek cerah bagi peternakan Indonesia, mengingat kebutuhan sapi bakalan untuk penggemukan selalu meningkat setiap tahun dan sangat tergantung pada usaha perbibitan yang dikelola oleh peternak rakyat. Hal ini merupakan peluang besar untuk menghasilkan sapi bakalan dari dalam negeri sendiri sehingga tidak perlu melakukan impor dari luar. Selain itu, tingginya kebutuhan bakalan akan memberikan keuntungan bagi peternak sapi potong. 
Hingga saat ini belum banyak peternak rakyat yang tertarik dalam usaha perbibitan sapi potong dengan skala besar. Sebagian besar hanya dilakukan dalam skala usaha kecil dan sebagai usaha sambilan dengan sistem pemeliharaan secara tradisional dan penerapan teknologi sangat sederhana. Kemampuan peternak dalam menghasilkan ternak khususnya untuk bibit masih sangat terbatas, karena pada usaha perbibitan sapi potong membutuhkan investasi yang cukup besar (Emawati et al. 2008), jangka waktu menghasilkan cukup lama sehingga membutuhkan waktu yang relatif panjang untuk memelihara. Senada dengan pernyataan Santoso et al. (2012) bahwa untuk menghasilkan pedet atau sapi bakalan memerlukan biaya yang relatif mahal, terutama biaya untuk pakan.

Sulawesi Tengah merupakan salah satu wilayah yanTengah saat ini mencapai 311.328 ekor (Ditjennak \& Keswan 2016). Dari total populasi teg ditetapkan sebagai wilayah pengembangan kawasan pertanian nasional, khususnya prioritas komoditas peternakan (Kementan 2016). Populasi sapi potong di Sulawesi rsebut sekitar 95\% berada di peternakan rakyat yang tersebar pada 13 wilayah kota/kabupaten. Khusus di wilayah Kabupaten Sigi populasi sapi potong mencapai 29.186 ekor (BPS Sulteng 2016) atau sekitar $10,67 \%$ dari total populasi Sulawesi Tengah. Pemeliharaan sapi potong di Kabupaten Sigi sebagian besar dikelola secara ekstensif, pemeliharaan induk-anak dilakukan secara bersama (cow calf operation) dengan jumlah pemilikan 2-4 ekor/peternak. Pemeliharaan induk-anak sebagai penghasil bakalan kurang diminati oleh pengusaha/pemodal karena dibutuhkan waktu pemeliharaan cukup panjang dan secara ekonomis kurang menguntungkan (Murtiyeni et al. 2011).

Di Kabupaten Sigi beberapa peternak telah melakukan usaha perbibitan sapi potong yang dikelola secara bersama terhimpun dalam satu kelompok ternak (Poknak). Salah satunya kelompok ternak Bualo Jaya di Desa Pandere, Kecamatan Gumbasa, Kabupaten Sigi. Usaha perbibitan sapi potong yang dikelola kelompok tersebut telah berjalan sejak tahun 2013 hingga saat ini ( \pm 4 tahun). Meskipun demikian, sejauh ini belum diketahui sejauh mana tingkat kelayakan usaha yang telah dijalankan. Berdasarkan hal tersebut maka dilakukan kajian yang bertujuan untuk mengetahui dan menganalisis kelayakan usaha perbibitan sapi potong pada kelompok ternak Bualo Jaya.

\section{MATERI DAN METODE}

Pengkajian dilaksanakan pada bulan Januari-Desember 2016 di Desa Pandere Kecamatan Gumbasa Kabupaten Sigi, Sulawesi Tengah. Penentuan lokasi ditetapkan dengan pertimbangan bahwa lokasi ini merupakan salah satu lokasi kegiatan pendampingan pengembangan kawasan peternakan sapi potong yang dilaksanakan oleh Badan Litbang Pertanian melalui BPTP Sulawesi Tengah. Penelitian menggunakan metode observasi langsung di lapangan dan survei dengan melibatkan 30 orang peternak sebagai responden. Responden merupakan anggota kelompok ternak Bualo Jaya dengan kriteria telah memelihara sapi betina induk minimal 1 (satu) tahun atau pernah beranak 1 (satu) kali.

Data yang dikumpulkan terdiri dari data primer dan data sekunder. Data primer diperoleh langsung dari responden melalui wawancara dengan menggunakan kuesioner. Data sekunder diperoleh dari instansi/dinas teknis yang terkait dengan penelitian ini. Data sekunder dan data primer dianalisis secara deskriptif serta dilakukan analisis kelayakan, pendapatan dan titik impas (break even point/BEP). Analisis kelayakan, pendapatan dan BEP didasarkan atas segala biaya yang dikeluarkan sejak awal pemeliharaan 30 ekor sapi betina (1 ekor/peternak) hingga menghasilkan pedet lepas sapih. Analisis pendapatan mengacu pada Rusdiana et al. (2010). Analisis untuk mengetahui kelayakan dan keuntungan dengan rumus sebagai berikut: 


$$
\begin{aligned}
& \mathrm{R} / \mathrm{C} \text { ratio }=\frac{\mathrm{TR}}{\mathrm{TC}} \quad \Pi=\mathrm{TR}-\mathrm{TC} \\
& \mathrm{R} / \mathrm{C}: \text { imbangan penerimaan dan biaya } \\
& \mathrm{TR}: \text { penerimaan total (total revenue) } \\
& \mathrm{TC}: \text { biaya total (total cost) } \\
& \Pi \quad: \text { keuntungan (benefit) }
\end{aligned}
$$

Mengacu pada Rusdiana et al. (2010) analisis titik impas bertujuan untuk mengetahui berapa volume produksi minimal yang tidak mengakibatkan perusahaan mengalami kerugian produksi disebut Break Even Point Quality (BEP Q) analysis. Sedangkan tingkat harga di mana besarnya penjualan minimal tidak mengakibatkan usaha mengalami kerugian disebut Break Even Point Selling (BEP S) yang dinyatakan dalam rupiah.

Dalam pengkajian ini BEP volume produksi (BEP Q) dan BEP harga (BEP S) diperoleh dari perhitungan menurut Rusdiana et al. (2010) dengan rumus:

$$
\begin{aligned}
& \text { BEP volume produksi }=\frac{\text { Total biaya produksi }}{\text { Harga penjualan pedet/ekor }} \\
& \text { BEP harga }=\frac{\text { Total biaya produksi }}{\text { Jumlah pedet }}
\end{aligned}
$$

\section{HASIL DAN PEMBAHASAN}

\section{Karakteristik peternak responden}

Karakteristik responden pada usaha perbibitan sapi potong di kelompok ternak Bualo Jaya disajikan pada Tabel 1. Berdasarkan umur, terlihat bahwa sebagian besar peternak responden termasuk kategori produktif, yaitu 73,33\% berumur 26-44 tahun. Takdir \& Munier (2013) melaporkan bahwa umur produktif peternak sapi pada kegiatan pendampingan PSDS-K di Sulawesi Tengah rata-rata berumur 43,8 tahun. Tingkat pendidikan peternak responden termasuk cukup tinggi yaitu 53,33\% lulus SLTA, menggambarkan bahwa peternak memiliki motivasi yang tinggi dalam mengelola usaha peternakan yang dijalani. Soeharsono et al. (2013) mengemukakan bahwa peternak berumur rata-rata 41 tahun dan tingkat pendidikan SMP-SMA memungkinkan dapat dengan mudah menerima inovasi teknologi usahatani menuju perubahan, baik secara individu maupun kelompok.

Peternak responden memiliki pekerjaan utama sebagai petani dan memiliki ternak sekitar 1-3 ekor/KK dengan pengalaman usaha beternak lebih dari 11 tahun. Hal ini menunjukkan bahwa meskipun usaha beternak bukan sebagai pekerjaan utama, namun rata-rata responden telah memiliki pengalaman dalam memelihara sapi walaupun dengan jumlah yang sedikit sebagai tambahan pendapatan. Trigestianto et al. (2013) menyatakan bahwa berdasarkan hasil analisis regresi terdapat hubungan antara jumlah keluarga dan jumlah ternak yang dipelihara terhadap kesejahteraan peternak sapi potong dengan koefisien determinasi (R2) diperoleh sebesar 0,418. 
Tabel 1. Karakteristik responden usaha perbibitan sapi potong di kelompok ternak Bualo Jaya

\begin{tabular}{lcc}
\hline \hline Karakteristik & Jumlah responden & Persentase (\%) \\
\hline Umur (tahun) : & 0 & 0 \\
$15-25$ & 22 & 73,33 \\
$26-44$ & 8 & 26,66 \\
$>45$ & & \\
Pendidikan formal & 9 & 30,00 \\
Tamat SD & 5 & 16,67 \\
Tamat SLTP & 16 & 53,33 \\
Tamat SLTA & & \\
Pekerjaan & 22 & 73,33 \\
Petani & 6 & 20,00 \\
Buruh tani & 2 & 6,67 \\
Wiraswasta dan lainnya & & \\
Kepemilikan ternak (ekor) & 16 & 53,33 \\
$1-3$ & 10 & 33,33 \\
$4-6$ & 4 & 13,33 \\
$>7$ & & \\
Pengalaman beternak (tahun) & 5 & 16,67 \\
$1-5$ & 9 & 30,00 \\
$6-10$ & 16 & 53,33 \\
$>11$ & &
\end{tabular}

\section{Profil usaha perbibitan}

Kelompok ternak Bualo Jaya berkedudukan di Desa Pandere Kecamatan Gumbasa Kabupaten Sigi. Kelompok ini telah menjalankan usaha perbibitan sapi potong sejak tahun 2013 hingga saat ini dengan jumlah anggota sebanyak 30 orang. Sapi betina induk yang dipelihara oleh peternak responden di kelompok ternak Bualo Jaya sebagian besar adalah sapi Peranakan Ongole (PO) dengan kisaran umur 3-7 tahun, telah beranak 1-3 kali dan merupakan milik pribadi tetapi milik kelompok (gaduhan).

Usaha perbibitan sapi potong yang dikelola masih dalam skala kecil dan sebagai usaha sampingan untuk menambah penghasilan keluarga peternak serta belum menerapkan inovasi teknologi secara optimal. Sistem pemeliharaan secara semi intensif, yaitu pada pagi-sore hari ternak dilepas di lahan perkebunan kelapa atau kakao, pematang sawah atau di lahan sawah setelah panen padi, sedangkan pada malam hari ternak dikandangkan bersama dalam satu kandang komunal. Bangunan kandang komunal milik kelompok sebanyak 1 (satu) unit berukuran 17 meter $\times 8$ meter yang dibangun di atas tanah seluas 40 $\mathrm{m}^{2}$ milik ketua kelompok.

Sistem perkawinan ternak yang diterapkan responden dilokasi kajian sebagian besar dengan cara kawin alam (73,3\%) dan inseminasi buatan (IB) (26,7\%). Sedangkan sistem pemberian pakan tambahan seperti dedak padi hanya diberikan jika bahan tersebut tersedia, waktu pemberian pun hanya disaat ternak berada dalam kandang pada malam hari. Hal ini disebabkan karena kesulitan memperoleh dedak padi, hanya tersedia pada saat musim panen padi (3-4 bulan). Pemanfaatan jerami padi untuk pakan ternak dilakukan 
secara berkelompok saat musim panen. Jerami padi dikumpulkan dari areal persawahan saat panen dan selanjutnya disimpan dalam bangunan bank pakan yang ada di areal kandang kelompok. Sesuai dengan pendapat Sodiq et al. (2010) sistem perpaduan usaha tanaman padi dan ternak sapi potong akan meningkatkan keefisienan usahatani karena dapat memanfaatkan masukan dalam (internal input), yang berarti akan mengurangi penggunaan masukan luar (external input) yang harus dibeli. Oleh karena itu sistem perpaduan tanaman-ternak perlu dikembangkan dalam rangka pembangunan peternakan berkelanjutan.

\section{Aspek kinerja reproduksi sapi betina}

Kinerja reproduksi sapi betina induk yang dipelihara oleh responden memiliki nilai $\mathrm{S} / \mathrm{C}$ yang tinggi (2,5 kali) dan jarak beranak (CI) yang relatif panjang (16,5 bulan). Hal ini berdampak pada biaya yang dikeluarkan untuk pemeliharaan dalam satu periode beranak juga semakin besar. Menurut Emawati et al. (2008) jarak beranak (calving interval) dan service per conception (S/C) sangat berpengaruh pada biaya dan penerimaan usaha perbibitan sapi potong. Kinerja reproduksi sapi betina induk pada usaha perbibitan di kelompok ternak Bualo Jaya ditampilkan pada Tabel 2.

Tabel 2. Kinerja reproduksi sapi betina induk pada usaha perbibitan sapi potong di kelompok ternak Bualo Jaya

\begin{tabular}{lc}
\hline \hline Uraian & Rata-rata \pm SD \\
\hline Umur (tahun) & $3,52 \pm 0,6$ \\
Skor kondisi tubuh (body condition score/BCS) & $3,5 \pm 0,5$ \\
Birahi setelah beranak (bulan) & $2,9 \pm 0,4$ \\
Kawin setelah beranak (bulan) & $3,3 \pm 0,4$ \\
Service per conception/S/C $($ kali) & $2,5 \pm 0,5$ \\
Jarak beranak (calving interval/CI) (bulan) & $16,5 \pm 0,5$ \\
\hline
\end{tabular}

\section{Analisis usaha perbibitan sapi potong}

Biaya-biaya yang diperhitungkan pada usaha perbibitan sapi potong dalam penelitian ini adalah total biaya produksi dan nilai penerimaan. Total biaya produksi terdiri dari biaya tetap dan biaya variabel yang dikeluarkan oleh kelompok ternak Bualo Jaya selama pemeliharaan, dengan asumsi; pemeliharaan sapi betina awal bunting sampai beranak (9 bulan), pemeliharaan pedet pra sapih (3 bulan) dan pemeliharaan pedet lepas sapih (15 bulan) sampai siap dijual, sehingga jangka waktu pemeliharaan secara keseluruhan adalah selama 27 bulan. Nilai penerimaan yang diperoleh terdiri dari penjualan produk utama (pedet) dan penjualan kotoran ternak (pupuk organik).

Pada Tabel 3 ditunjukkan bahwa total biaya produksi yang dikeluarkan pada usaha perbibitan selama 27 bulan sebesar Rp. 169.055.800. Dari total biaya produksi tersebut biaya tertinggi dikeluarkan untuk pembelian 30 ekor sapi betina yang dijadikan induk bibit (Rp.5.500.000/ekor). Menurut Hartono (2011) bahwa sebagian besar pengeluaran pada usaha peternakan sapi dengan skala kecil digunakan untuk membeli bibit ternak relatif tinggi. 
Tabel 3. Analisis usaha perbibitan sapi potong untuk menghasilkan pedet lepas sapih skala 30 ekor induk selama 27 bulan

\begin{tabular}{lr}
\hline \hline Uraian & Nilai (Rp) \\
\hline I. Biaya produksi & \\
A. Biaya tetap & \\
Penyusutan kandang & 400.000 \\
Penyusutan peralatan & 25.000 \\
Pajak & 15.300 \\
Total biaya tetap & 440.300 \\
B. Biaya variabel & \\
Pembelian sapi betina 30 ekor (@Rp. 5.500.000/ekor) & 165.000 .000 \\
Pakan jerami padi & 200.000 \\
Pakan tambahan (dedak padi) & 750.500 \\
Pakan rumput gajah/raja & 300.000 \\
Vitamin dan obat-obatan & 75.000 \\
Inseminasi buatan (IB) 1-2 kali, 8 ekor (@Rp. 30.000/ekor) & 240.000 \\
Pemeriksaan kebuntingan (PKB) 2 kali, 30 ekor (@ Rp. 25.000/ekor/2x) & 750.000 \\
Tenaga kerja pengolahan pupuk organik & 600.000 \\
Tenaga kerja pemeliharaan pedet lepas sapih (15 bulan) & 700.000 \\
Total biaya variabel & 168.615 .500 \\
Total biaya produksi (A + B) & 169.055 .800 \\
II. Penerimaan & \\
A. Penjualan pedet lepas sapih 30 ekor (@Rp. 4.000.000/ekor) & 120.000 .000 \\
B. Penjualan pupuk organik 72.900 kg (@Rp. 1.250/kg) & 91.125 .000 \\
Total penerimaan (A + B) & 211.125 .000 \\
III. Hasil analisis & \\
Pendapatan bersih & 42.069 .200 \\
R/C ratio & 1,24 \\
BEP produksi (ekor) & \\
BEP harga/ekor & 5.635 .193 \\
\hline
\end{tabular}

Nilai pendapatan bersih dari usaha perbibitan sapi potong yang dikelola kelompok ternak Bualo Jaya selama pemeliharaan 27 bulan pada skala 30 ekor sapi betina induk hingga dapat menjual pedet lepas sapih diperoleh sebesar Rp. 42.069.200 dengan nilai $R / C$ ratio 1,24. Hal ini berarti bahwa setiap peningkatan biaya sebesar 1 satuan akan menghasilkan penerimaan sebesar 1,24 kali. Menurut Rusdiana et al. (2010) metode analisis $R / C$ ratio merupakan angka banding antara penerimaan dan biaya yang dikeluarkan pada suatu usaha dan dikatakan layak apabila angka $\mathrm{R} / C$ ratio-nya lebih besar dari 1. Dengan demikian usaha perbibitan sapi potong oleh kelompok Bualo Jaya dikatakan layak untuk dilanjutkan atau dipertahankan, namun pendapatannya masih perlu ditingkatkan agar usahanya optimal. Hal yang dapat peternak tempuh adalah meningkatkan jumlah pedet lepas sapi.

Analisis BEP merupakan salah satu teknis analisis ekonomi yang berguna dalam hubungan biaya variabel total dan biaya tetap total terhadap output produksi atau ukuran- 
ukuran lain dalam aktifitas bisnis dan industri (Gaspersz 2002). Analisis titik impas (BEP) digunakan untuk mengetahui hubungan antara beberapa variabel dalam kegiatan usaha, yang menggambarkan posisi biaya total sama dengan penerimaan total, dengan kata lain titik ini disebut titik impas usaha, dicapai dengan perhitungan jumlah pengeluaran dibagi harga ternak per ekor (Rusdiana et al. 2010). Dengan demikian titik impas usaha perbibitan sapi potong pada pengkajian ini diperoleh dengan perhitungan sebagai berikut:

BEP volume produksi $=\frac{\text { Total biaya produksi }}{\text { Harga penjualan pedet/ekor }}=\frac{\text { Rp. } 169.055 .800}{\text { Rp. } 4.000 .000}=42$ ekor

Secara sederhana jumlah pengeluaran selama usaha perbibitan sapi potong dibagi harga penjualan pedet/ekor diperoleh nilai 42 ekor. Hal ini berarti bahwa usaha yang dikelola dengan skala 30 ekor induk ternyata mencapai titik impas pada volume produksi sekitar :

$$
\text { BEP harga }=\frac{\text { Total biaya produksi }}{\text { Jumlah pedet }}=\frac{\text { Rp. } 169.055 .800}{30 \text { pedet } / \text { ekor }}=\text { Rp. 5.635.193/ekor }
$$

Hasil analisis usaha perbibitan sapi potong yang dikelola selama 27 bulan untuk dapat menjual pedet menggambarkan bahwa titik impas akan tercapai apabila pedet yang dihasilkan dari usaha perbibitan dijual minimal dengan harga Rp. 5.635 .193 per ekor.

\section{KESIMPULAN}

Usaha perbibitan sapi potong yang dikelola oleh kelompok ternak Bualo Jaya selama 27 bulan layak dan dapat dipertahankan sebagai sumber pendapatan tambahan bagi kelompok dan anggotanya. Nilai pendapatan bersih yang diperoleh adalah sebesar Rp. 42.069.200/30 ekor/27 bulan, R/C 1,24, titik impas (BEP) produksi 42 ekor dan BEP harga Rp. 5.635.193 per ekor.

\section{UCAPAN TERIMA KASIH}

Terima kasih disampaikan kepada ketua kelompok ternak Bualo Jaya bapak Ahmad Ladjumpa beserta seluruh anggotanya, teknisi peternakan bapak Aslan Lasenggo, Jajaran Disnakkeswan Kabupaten Sigi serta semua pihak yang telah bekerja sama selama kegiatan pendampingan pengembangan kawasan peternakan sapi potong tahun 2015-2016.

\section{DAFTAR PUSTAKA}

BPS Sulawesi Tengah. 2016. Sulawesi Tengah Dalam Angka. Palu (Indonesia): Badan Pusat Statistik.

Ditjennak dan Keswan. 2016. Statistik Peternakan dan Kesehatan Hewan 2016. Jakarta (Indonesia): Direktorat Jenderal Peternakan dan Kesehatan Hewan Kementerian Pertanian.

Emawati S, Widiati R, Budisatria IGS. 2008. Analisis investasi usahatani pembibitan sapi potong di Kabupaten Sleman. Bul Peternak. 32:224-234.

Gazpersz, V. 2002. Pedoman Penyusunan Rencana Bisnis. Jakarta (Indonesia): PT. Gramedia Pustaka Utama. 
Hartono, B. 2011. Analisis Ekonomi Rumah Tangga Peternak Sapi Potong di Kec. Damsol, Kabupaten Donggala, Propinsi Sulawesi Tengah. J. Ternak Tropika, 12(1), 60-70.

Kementan. 2016. Lokasi Pengembangan Kawasan Pertanian Nasional. Jakarta (Indonesia): Kementerian Pertanian. hlm. 43.

Murtiyeni, Juarini E, Wibowo B. 2011. Profil dan produktivitas pembibitan sapi potong sistem komunal pada peternakan rakyat di Kabupaten Kediri. Dalam: Prasetyo LH, Damayanti R, Iskandar S, Herawati T, Priyanto D, Puastuti W, Anggraeni A, Tarigan S, Wardhana AH, Dharmayanti NLPI, penyunting. Teknologi peternakan dan veteriner untuk peningkatan produksi dan antisipatif terhadap dampak perubahan iklim. Prosiding Seminar Nasional Teknologi Peternakan dan Veteriner. Bogor, 7-8 Juni 2011. Bogor (Indonesia): Puslitbang Peternakan. hlm.278-285.

Rusdiana S, Wibowo B, Praharani L. 2010. Penyerapan sumberdaya manusia dalam analisis fungsi usaha penggemukan sapi potong rakyat di pedesaan. Dalam: Prasetyo LH, Natalia L, Iskandar S, Puastuti P, Herawati T, Nurhayati, Anggraeni A, Damayanti R, Dharmayanti NLPI, Estuningsih SE, penyunting. Teknologi peternakan dan veteriner ramah lingkungan dalam mendukung program swasembada daging dan peningkatan ketahanan pangan. Prosiding Seminar Nasional Teknologi Peternakan dan Veteriner. Bogor, 3-4 Agustus 2010. Bogor (Indonesia): Puslitbangnak. hlm. 453-460 .

Santoso, Khalid, Warsito, Andoko A. 2012. Bisnis pengemukan sapi. Jakarta (Indonesia): PT Agro Media Pustaka.

Sodiq A, Munadi, Purbojo SW. 2010. Sistem Produksi Peternakan Sapi Potong Berbasis Sumberdaya Lokal pada Program Sarjana Membangun Desa (SMD). J Pembang Pedesaan. 10:61-68.

Soeharsono, Takdir M, Munier FF. 2013. Performan induk sapi lokal donggala yang dipelihara secara ekstensif di lembah Palu Sulawesi Tengah. Dalam: Djufry F, Baco D, Limbongan J, Sahardi, Matheus Sariubang M, Ella A, Tandisau P, Nappu MB, Ishak ABL et al., penyunting. Inovasi Pertanian Ramah Lingkungan. Prosiding Ekspose dan Seminar Nasional. Makassar, 19-21 Juni 2013. Bogor (Indonesia): Balai Besar Pengkajian dan Pengembangan Teknologi Pertanian. hlm. 218-224.

Takdir M, Munier FF. 2013. Kondisi peternak dan keragaan pengelolaan reproduksi sapi betina di lokasi pendampingan program PSDS-K Sulawesi Tengah. Dalam: Mardiana, Haryono P, Padang IS, Irmadamayanti A, Dewi M, Biolan $\mathrm{H}$ et al., penyunting. Akselerasi Inovasi dan Diseminasi Teknologi Menuju Kemandirian dan Ketahanan Pangan Berbasis Sumberdaya Genetik Lokal. Prosiding Seminar Nasional. Palu 18 Maret 2013. Bogor (Indonesia): Balai Besar Pengkajian dan Pengembangan Teknologi Pertanian. hlm. 1101-1111.

Trigestianto M, Nur S, Sugiarto M. 2013. Analisis tingkat kesejahteraan peternak sapi potong di Kabupaten Purbalingga. J Ilmiah Peternak. 1:1158-1164.

\section{DISKUSI}

\section{Pertanyaan}

Apakah tujuan pemeliharaannya untuk pembibitan atau penggemukan?

\section{Jawaban}

Untuk menghasilkan bibit sapi lokal, tepatnya budidaya sapi. 